\title{
Sugerencias didácticas para la enseñanza de la Geografía de la montaña
}

\author{
A. GOMEZ ORTIZ *
}

La montaña configura espacios de la superficie terrestre con particularidades geográficas propias, especialmente las derivadas de su medio físico. Los recursos económicos que las caracteriza, asi como su poblamiento e incluso la organización y costumbres de sus habitantes difieren de las tierras del llano. Mientras en estas últimas el impacto del hombre ha sido decisivo, en aquellas otras montañas su actuación se ha visto mermada y a veces condicionada por la propia naturaleza.

España es un país que alberga tierras de considerable altura, como lo demuestra la altitud media del conjunto de ellas. La configuración del solar hispano ofrece una orografía accidentada con un buen porcentaje de espacios montañosos fijados por encima de los $1.000 \mathrm{~m}$. ${ }^{1}$. En este sentido considerables grupos humanos asentados en estos medios se encuentran vinculados a las formas de vida de la montaña. Recordemos, por ejemplo, pueblecitos pirenaicos o cántabros o aquellos otros fijados en las laderas de las cordilleras Ibérica, Central o Béticas, por citar algunos casos. El entorno donde se ubican, muy diferente al del llano, proporciona inmejorables recursos didácticos para su estudio, de forma especial en lo referente a temas geográficos por las repercusiones que de ellos se desprenden en las diferentes áreas de conocimiento del "currículum escolar". Los profesores de enseñanzas básicas y medias han de ser sensibles a ello y debieran tenerlo

* Universidad de Barcelona.

' Del territorio peninsular el 17,2 por 100 supera los $1.000 \mathrm{~m}$. de altitud y el 59,01 por 100 se sitúa entre los 600 y $1.000 \mathrm{~m}$. Con respecto a Cataluña, de sus $31.930 \mathrm{~km}^{2}$ de superficie que posee, el 16,5 por 100 se inscribe en cotas por encima de los $1.000 \mathrm{~m}$. coincidiendo la casi totalidad de ellas en los Pirineos. Los espacios fijados entre 600 y 1.000 m. significan el 33,2 por 100. 
en cuenta a la hora de programar sus cursos, pues de esta forma contribuirían a realizar una enseñanza más dinámica y participativa al enraizarla en su entorno inmediato ${ }^{2}$. Además, y operando de esta manera, se cooperaría a la tan necesitada renovación pedagógica al introducir en los programas de los distintos niveles de enseñanza temas novedosos con incidencia efectiva en la creación de un espíritu crítico y responsable en los alumnos en cuanto a problemas medioambientales. También permitiría el aprendizaje o consolidación de determinadas técnicas o habilidades, tan útiles en la enseñanza de la Geografía.

Los apartados que a continuación siguen quieren ser, en la medida que permite la extensión de este artículo, unas reflexiones y sugerencias didácticas acerca de algunos temas centrales propios de medios montañosos. Trataremos dos grandes bloques temáticos y dentro de ellos algunos aspectos más sobresalientes. En primer lugar, la importancia del medio natural para continuar, después, con la agricultura y la ganadería como actividades económicas preponderantes de estos ámbitos montañosos. En términos generales los referidos bloques temáticos están pensados para alumnos del Ciclo Superior de EGB, aunque su estructura y desarrollo pueden amoldarse a otras parcelas científicas, especificas de niveles de enseñanzas medias.

\section{LA IMPORTANCIA DEL MEDIO NATURAL}

La vida humana en la montaña se encuentra, en gran manera, supeditada al medio biofísico. Su estudio debe considerarse para la comprensión de los diferentes modos de vida de los hombres. Pero su enfoque debe mostrarse pluridisciplinar, perdiendo, si es preciso, profundidad de contenidos científicos en determinadas ramas del saber, pero ganando, a cambio, un entendimiento global del paisaje y de las comunidades que lo habitan.

Existen unos elementos físicos y otros biológicos que definen a la montaña. Ambos configuran el conjunto biofísico en el que el grupo social ha-

${ }^{2}$ Algunas ideas al respecto pueden encontrarse en A. GOMEZ ORTZ, "La Geografia i les Ciencies Socials en el Cicle Mitjá d'EGB", Butlletí dels Mestres, Generalitat de Catalunya. Barcelona 1983, pp. 2-3. También y del mismo autor, Los itinerarios pedagógicos como recurso didáctico en la enseñanza de la Geografía en la EGB, IX Coloquio de Geografía. Murcia 1985. 
bitante organiza su vida. Entre grupo social y medio biofísico existen una serie de relaciones de dependencia y que, en la mayoría de las veces, adquieren mayor rango las derivadas del medio natural. En base a ello la organización de la actividad humana en la montaña se encuentra, en buen grado, supeditada al medio por lo que su estudio es sumamente beneficioso para comprender, no sólo los tipos de vida de las comunidades que pueblan las montañas, sino también para conocer los tipos y distribución de los paisajes que las caracterizan.

De entre los diversos componentes que definen al medio biofísico de la montaña trataremos dos: el clima y el relieve, pues son los más significativos. De cada uno de ellos se reseñarán algunas repercusiones en el campo didáctico, a manera de sugerencias prácticas.

\section{El clima}

Los regímenes de precipitación y temperatura junto con los vientos son los elementos que mejor califican a los climas de montaña. De su comportamiento depende la fijación del poblamiento humano, así como la actividad agropastoril, principalmente. También colabora en la determinación y selección de la cobertura vegetal y en el tipo, forma e intensidad de la erosión.

Algunos objetivos que deben alcanzarse en el tratamiento del clima de montaña son:

- Percatarse que ofrece importantes diferencias con respecto al del llano próximo.

- Comprender que a lo largo del año presenta dos estaciones marcadas: una fría y otra cálida.

- Relacionar la variación de la temperatura en altura con los diferentes estratos vegetales.

- Razonar la existencia de determinados cultivos y la ausencia de otros propios del llano.

- Dominar el manejo de algunos aparatos meteorológicos, logrando interpretar su información. 
- Representar mediante gráficos los datos suministrados por la información meteorológica.

Como actividad inicial en el estudio del clima se analizarán los datos de dos estaciones meteorológicas, una de montaña y otra de llano. La realización y comentario de sus climogramas pondrán de relieve unos contrastes, especialmente referidos al ritmo térmico. Es aconsejable que ambos climogramas correspondan a localidades de la misma comarca, para lograr establecer mejor relaciones y comparaciones ${ }^{3}$. El sistema de representación del climograma es recomendable que siga la normativa de $\mathrm{H}$. Gaussen y así poder apreciar mejor períodos áridos, si los hubiere.

Como localidades de referencia a continuación detallamos los datos de dos grupos de ellas. Bacares y Albox en la provincia de Almería, como representativas de la España seca ${ }^{4}$. Estas se ubican en el valle del Almanzora. La primera (Fig. 1), en su tramo alto, en plena Sierra de los Filabres, a $1.201 \mathrm{~m}$. de altitud, y la segunda, a 423 m., inmersa en el surco intrabético.

El segundo grupo de localidades pertenece a la provincia de Huesca,en medios climáticos distintos. Torla, en el valle pirenaico de Broto, a $905 \mathrm{~m}$. de altitud y Monzón (Fig. 2), en la depresión del Ebro, a 270 m., en el curso final del Cinca ${ }^{5}$. Lo que interesa del conjunto de ellas es establecer comparaciones, entre Albox-Bacares, Monzón-Torla y Bacares-Torla, para de esta manera poder explicar las causas del comportamiento térmico y pluviométrico y sus consecuencias en el medio. También será motivo para referirnos a la aridez, tras haber efectuado los climogramas correspondientes.

A grandes rasgos y a la vista de los datos que reflejan las mencionadas estaciones podemos resaltar:

a) Los valores anuales de temperatura y pluviosidad son diferentes. Como hecho común a los dos grupos de estaciones se detecta mayor pluviosidad a mayor altura y mayor temperatura a menor altitud.

${ }^{3}$ La obtención de datos al respecto se encontrarán en las publicaciones del Instituto Nacional de Meteorologia (Guia resumida del clima de España, Boletin Mensual Climatológico, Boletín Meteorológico Diario, etc.).

${ }^{4}$ Los datos termopluviométricos de ellas han sido obtenidos de J. CaPel Molina, El clima de la provincia de Almería, Monte de Piedad y Caja de Ahorros de Almería. Almería 1977.

${ }_{5}^{5}$ Los datos termopluviométricos de ellas han sido obtenidos de M. LISO PUENTE y A. AsCAso LIRIA, Introducción al estudio de la evapotranspiración y clasificación climática de la cuenca del Ebro. Anales de la Estación Experimental de Aula Dei. CSIC. Zaragoza 1969. 
b) Menor número de meses áridos en las estaciones de montaña que en las del llano. Para Bacares cuatro meses (j. jl. ag. s.) frente a siete en Albox (e. f. my. j. jl. ag. y s.). Las referidas a la provincia de Huesca reflejan cero meses en Torla y dos en Monzón (jl. y ag.).

c) Diferente repercusión de la lluvia entre las dos estaciones de montaña. Bacares $(415,8 \mathrm{~mm}$.) ofrece cuatro meses con falta de agua en el suelo, mientras que Torla $(1.470 \mathrm{~mm}$.) a lo largo del año manifiesta suficiente agua y a veces con superavit de ella. Las causas que generan estos hechos en el tipo de cubierta vegetal son determinantes, de manera especial en la calidad de los pastos y en los tipos de cultivos.

En base a los datos obtenidos en ambos grupos de localidades puede realizarse una comparación con los referidos a nuestra población, en caso de disponer de ellos. Si no los hubiere nos servirán de apoyo los de alguna estación cercana, con similitudes geográficas a la nuestra. De todas formas es necesario que el centro escolar disponga de una pequeña estación meteorológica dotada con los principales aparatos (termómetros, pluviómetro, barómetro, anemómetro, etc.). De esta manera los alumnos se ejercitarán en su manejo al realizar lecturas períodicas. Ni que decir que estas observaciones deben prolongarse durante un buen tiempo y así poder disponer de suficiente material informativo para la confección de los gráficos correspondientes (diagramas, curvas de frecuencia, histogramas, etc.).

El estudio del clima y la comprensión del ritmo termopluviométrico, principalmente, servirán de punto de partida para el logro de otros objetivos específicos, aunque en ocasiones precisa que se les dedique el tiempo necesario. Un tema muy relacionado con el clima es la vegetación, su distribución y especies dominantes. En este sentido es conveniente que los alumnos conozcan razonadamente las causas de su estratificación a lo largo de las laderas y más aún si el término municipal donde habita el grupo clase posee tales características biogeográficas. La determinación de las especies vegetales así como las alturas que cubren (estrato de caducifolios, estrato de coníferas y estrato de prados naturales) son a su vez motivo para generar otros tipos de cuestiones relacionadas con el clima. Así, y utilizando el gradiente término altitudinal medio ${ }^{6}$ se podrá obtener una apreciación de la temperatura a diferentes alturas y establecer relaciones con las necesidades biológicas de las plantas.

\footnotetext{
${ }^{6}$ Recuérdese que se define como el descenso que sufre la temperatura a medida que se alcanza mayor altitud. El valor medio anual es del orden de $0,55^{\circ} \mathrm{C}$ por cada $100 \mathrm{~m}$.
} 
ALBOX, 423 m.

$t \% m$

pl $(\mathrm{mm})$

30,6

20,4

16,4

39,7

42,5

9,9

14,1

37,0

J.

ال

$\mathrm{Ag}$.

S.

O.

N.

Año

16,2

29,7

4,5

60,7

3,9

36,0

4,7

26,3

My.

20,5

21,4

16,8

18,7

2,8

20,4

6,2

27,0

6,3

20,5

7,4

27,2

20,0

16,8

19,4

.

20,1

54,2

11,6

51,3

15,6

39,7

7,5

58,1

49,5

45,2 
MONZON, $270 \mathrm{~m}$.

$\mathrm{t} / \mathrm{m}$

$\mathrm{pl}(\mathrm{mm})$

39

31

30

35

36

57

48

31

34

52

45

31

9,7

14,8

469

10,9
124

4,0

136

4,4

121

7,6

159

9,9

94

13,7

87

16,4

131

19,6

61

17,4

81

141

157

11,6

6,4

178

Año

$\begin{array}{llll}14,8 & 469 & 10,9 & 1.470\end{array}$


También, y en este mismo orden de cosas, puede suscitarse el tema de la explotación forestal e investigar sobre algunos aspectos de ella. Su interés es excepcional para los pueblos de la España húmeda, más cuando la titularidad de los bosques es patrimonio del municipio. En este orden de cosas asuntos como la selección de los espacios a talar, su periodicidad, los incendios, la repoblación forestal, el papel del ICONA, etc. son cuestiones que pueden generar importantes debates y trabajos, motivando en el alumno un interés por los problemas de su municipio y que le atañen muy directamente. El resultado obtenido puede ordenarse y quedar reflejado en una serie de posters y dossiers.

Otra actividad ligada estrechamente con el clima es el tema de las aguas. En este sentido relacionar el régimen de precipitaciones (lluvia/nieve) del invierno y primavera pasadas y tratar de establecer conexiones con la abundancia o escasez del elemento líquido en los manantiales, pozos y ríos que posea el municipio puede resultar interesante, más cuando haya existido restricción de agua potable en algunas épocas. El debate, si se presenta de esta forma, puede enriquecerse con cuestiones de diversa índole; desde las consecuencias que genera la sequía en la población, cultivos y ganados (recuérdese, por ejemplo, el estado de "alerta roja» durante 1984 en muchos pueblos españoles) hasta aquellas otras que suscitan la necesidad de una política de aguas.

Asimismo, otro tema interesante a debatir y relacionado con las lluvias torrenciales es el derivado de los estragos, a veces catastróficos, que pueden ocasionar las aguas en determinados medios, especialmente montañosos. En este sentido, por ejemplo, basta hacer un relato de los desastres generados por los desmesurados aguaceros de noviembre de 1982 en Andorra y buena parte del Pirineo catalán, o los acaecidos por idénticas causas en la costa granadina. Tanto en un caso como en otro las consecuencias emanadas por el cuantioso volumen de agua encauzada por torrentes y rios fueron catastróficas, como lo delataron las inundaciones en campos de cultivo y poblaciones (con pérdidas humanas), la desaparición de no pocos tramos de carreteras y pistas forestales, los deslizamientos a lo largo de las laderas, etc. Afrontar un estudio de las zonas con riesgo de siniestro del municipio montañoso en que se ubica la escuela, si las hubiere, es una temática que suscita un buen número de trabajos al alcance de los alumnos de los que podrán obtenerse enriquecedores debates. 


\section{El relieve}

El relieve, como armazón físico donde se emplazan los espacios montañosos permite también un buen número de actividades, convirtiéndose en elemento de estudio excepcional. El mapa topográfico, la foto aérea y el trabajo de campo son adecuados puntos de arranque, de ahí que su utilización deban ser tenidos muy en cuenta por el profesor.

Una salida por los alrededores de la localidad permitirá asimilar una serie de cuestiones básicas que diferencian los medios montañosos de los del llano y que en el mapa a gran escala $(1 / 10.000,1 / 5.000,1 / 1.000)$ están inmersas, aunque habrá que descubrirlas. Entre éstas cabrian destacarse la pendiente de las laderas, la adecuación al relieve de la forma y dimensión de los campos, la orientación de los núcleos de población, la fijación de los bosques, de los pastos y de los espacios agrarios, etc. En base a ello la interpretación del mapa topográfico dejará de ser algo abstracto y se convertirá en un documento útil que refleja una realidad tangible.

Algunos objetivos especificos que pueden lograrse en el estudio del relieve son:

- Identificar en el mapa topográfico a media escala (1/50.000, $1 / 100.000$ ) el llano y la montaña. Igualmente diferenciar las principales formas del relieve (fondos de valle, vertientes, superficies abruptas, superficies planas, línea de cumbres, puntos culminantes, etc.).

- Detectar en un mapa topográfico a gran escala (1/25.000, 1/10.000, $1 / 5.000$ ) la configuración general de las tierras del municipio montañoso. Asimismo la red fluvial, los núcleos de población y las vías de comunicación.

- Distinguir también en el mismo mapa el uso del suelo (espacios agrícolas, forestales, improductivos, etc.) haciendo referencia a los topónimos con que se conocen.

- Realizar ejercicios de cálculo en base a la escala del mapa topográfico elegido (longitudes, superficies, alturas). Confeccionar perfiles con medición de pendientes. 
- Cartografiar sobre el mapa, mediante simbologia a convenir, la diferente utilidad del suelo del término municipal.

- Comprender los motivos por los que el territorio presenta una diversidad en el uso del suelo.

El estudio del relieve podría iniciarse, como se señaló, con una salida a diferentes puntos significativos del municipio, los que se localizarian, durante el trayecto, en el mapa topográfico ${ }^{7}$. Tal actividad es necesario que fuese completada con la realización de fichas de observación preparadas al efecto, en las que se solicitara del alumno la respuesta a una serie de cuestiones (nombre del lugar o paraje, altitud, uso del suelo, distancia de la población, etc.) y actividades (realizar un croquis de la forma dominante del relieve, recoger muestras de rocas y plantas, etc.).

Posteriormente, una actividad sumamente útil es la confección de una maqueta del relieve del municipio a base de la superposición de planchas de corcho. Tal superposición, a intervalos a convenir por nosotros, vendría dada por las curvas de nivel maestras que el mapa topográfico a gran escala refleja. La referida maqueta permitirá tener una visión global del relieve municipal, después de haber sido completada con la información pertinente (red fluvial, usos del suelo, comunicaciones, núcleos de población, etc.).

Especial importancia presenta en este apartado del relieve descubrir las razones que explican la ubicación de los cultivos, bosques, pastos y asentamientos humanos en el conjunto municipal. Su distribución en el espacio montañoso no es al azar sino que responde a razones lógicas, transmitidas de padres a hijos y que, casi siempre, están intrínsecamente avaladas por el comportamiento de la naturaleza. Así, los pueblos se fijan encarados a mediodía para poder recibir mejor los rayos del sol, especialmente durante los meses fríos. También se asientan los campos de labor en idéntica orientación, pues las plantas cultivadas (patatas, determinados árboles frutales, forrajes, cereales de invierno y primavera, etc.) exigen temperaturas elevadas durante los períodos de germinación y maduración, generalmente a lo largo de los meses cá-

7 Excelentes mapas topográficos a escala $1 / 50.000$ y $1 / 100.000$ pueden localizarse en el IGN (Instituto Geográfico Nacional, calle General Ibáñez de Ibero, 3 (Madrid) o Delegaciones regionales. Para escalas de más detalle hay que acudir a las Corporaciones Locales o a los respectivos departamentos de los Gobiernos Autónomos, pues el IGN sólo dispone de la cobertura de determinadas comarcas. En todos estos organismos oficiales también es fácil que dispongan de fotografías aéreas. 
lidos. Alrededor del núcleo de población no es extraña tampoco la presencia de parcelas dedicadas a la obtención de hortalizas durante el verano, las que se riegan gracias a las aguas que se canalizan por las acequias y que arrancan de manantiales o del propio rio.

La localización de los bosques en la umbría y el de los pastos naturales a partir de determinadas alturas es una imposición de la naturaleza y que el hombre de la montaña respeta muy bien. Ahora, el clima (régimen termopluviométrico, principalmente) tiene diferente comportamiento que en solana, pues es más frío y húmedo, condición poco adecuada para los cultivos y para el confort humano. Todas estas razones generales y otras particulares en cuanto a la utilización del espacio por parte de las comunidades montañesas, han de ser captadas por los alumnos para de esta manera entender el uso del espacio y hacer de él un empleo racional.

Entendidos los motivos que explican la utilización del suelo no resultará difícil confeccionar un mapa municipal, con fondo topográfico, del uso de la tierra. Para ello un excelente auxiliar resulta la fotografía aérea. La delimitación de los espacios con una simbología establecida, permitirá disponer de una visión global del territorio. En base a ello se podrán mensurar las diferentes superficies clasificadas y establecer los porcentajes de usos de la tierra y sus respectivos diagramas. En tal sentido la documentación de los archivos municipales (censo, catastro) y la encuesta directa a los habitantes del lugar son puntos de partida de gran valor informativo.

\section{GANADERIA Y AGRICULTURA: ACTIVIDADES ECONOMICAS PREPONDERANTES}

La economia de los espacios montañosos habitados se encuentra muy supeditada al medio natural. De ahí que el sector primario sea el preponderante, aunque desde hace algunos lustros el turismo, especialmente, aunque no en todos los ámbitos montanos, haya modificado la tradicional estructura económica. La oposición que en determinadas épocas existió entre campo-ciudad son todavía válidas para la montaña y la ciudad. La montaña, a pesar del impacto de la ciudad y de los medios de comunicación social, es aún rural y ganadera por lo que sus gentes se organizan de diferente manera que aquellas otras del llano o de la urbe. 
La mayoría de los pueblos de montaña son agrícolas o ganaderos o combinan ambas actividades como ocupaciones principales. La raíz de ello puede estar en las condiciones geográficas de su medio, de manera especial en las características de la orografia y en el clima dominante. Hay pueblos montañeses en los que predomina la agricultura, como los que salpican las laderas de la Penibética y los hay nítidamente ganaderos como los fijados en las montañas astur-leonesas o pirenaicas. La diferencia fundamental es la existencia de pastos frescos en verano. Hasta tal punto son ganaderos estos últimos pueblos que la agricultura que poseen la enfocan hacia el mantenimiento de su cabaña; es decir, se trata de una agricultura dirigida a la alimentación del ganado, mediante la obtención de forrajes (hierba o tubérculos). Unos ejemplos ilustrarán estos hechos. En la comarca de la Cerdanya (Lérida-Gerona), en pleno Pirineo Oriental, más del 50 por 100 de su superficie regada se dedica a la hierba y algunos de sus pueblos, como Alp, fijado a $1.158 \mathrm{~m}$. de altitud, y Guils de Cerdanya, a $1.385 \mathrm{~m}$., llegan al 100 por 100. En este mismo sentido el municipio de Meranges, a $1.539 \mathrm{~m}$. de altura, en la misma comarca, de las $3.738 \mathrm{Ha}$. que posee el 54,9 por 100 de ellas están destinadas a prados y pastos y sólamente el 3,5 por 100 a la agricultura tradicional (cereales, patatas y algunos frutales) (Fig. 3).

En el otro extremo los pueblos de montaña dedicados a la agricultura tienen organizada su economía de forma distinta. Ahora es el producto de la tierra lo que importa, porque en ella está su riqueza. El ganado, si lo tienen, es algo secundario. Lo conforman ovejas y cabras, principalmente, y se le envía a pastar a los rastrojos, al monte bajo o a los escasos prados de las alturas. Los cultivos pocas veces se subordinan a aquél, puesto que su finalidad es alimentar al campesino o servir, tras su venta, como fuente de ingresos.

Algunos objetivos generales a perseguir en el tratamiento de estos temas podrían ser:

- Valorar la importancia de la ganadería y de la agricultura en los pueblos de montaña.

- Definir las causas que motivan la preponderancia de la ganadería y/o la agricultura en los pueblos montañeses.

- Razonar acerca del predominio de determinados cultivos o ganados. 
- Interpretar datos estadísticos de producción ganadera o agricola logrando su transformación en gráficos.

- Conocer los regímenes de tenencia y explotación de los pastos valorando su significado en la economía municipal.

- Establecer diferencias de diversa índole entre pueblos de montaña y del llano.

Al afrontar estos temas económicos, agricultura y ganadería, es necesario ofrecerlos de manera que en su explicación intervengan causas de diferente orden, para de esta manera significar que la economía es fruto de la interacción de hechos diversos. En ello un primer paso consistirá en descubir cuál es la principal fuente económica de nuestro núcleo de población e investigar las razones que lo explican. En un principio no resultará difícil deducirlo al analizar la ocupación predominante de sus habitantes, aunque en un paso posterior habrá que demostrarlo con argumentación razonada.

\section{La ganadería}

Una de las facetas que más atención debe despertar hacia el conocimiento de los pueblos de la montaña es el estudio de la ganadería trashumante y el de los pastos de verano. A este respecto un estudio de las cañadas resultará de suma utilidad (Fig. 3), de manera especial para resaltar el valor económico de los pastizales de verano ${ }^{8}$.

Algunos aspectos a tratar en la investigación referida podrian ser:

- Identificación de la existencia o no de cañadas en el término municipal.

- Cartografiar sobre el mapa municipal o comarcal los recorridos que siguen los ganados hacia los pastos.

${ }^{8}$ Estos conceptos (trashumancia y cañada) es conveniente que sean ampliados por el profesor. Encontrará información suficiente en J. VILA VALENTi, La Península lbérica. Ariel. Barcelona 1968, pp. 247-249 y p. 376. También en J. VICENS VIVES, Historia Económica de España. Vicens-Universidad. Barcelona 1977, pp. 232-236. 
- Régimen jurídico y uso de los pastos.

- Procedencia y volumen de cabezas de ganado que transita hacia los pastizales. Fechas de remonte y descenso.

- Forma de vida del vaquero o pastor durante su estancia con el ganado ${ }^{9}$.

El tema que estamos refiriendo podría completarse con un estudio acerca de los cuidados que recibe el ganado durante el invierno. Generalmente los rebaños de ovejas tienden a descender al llano, a los pastos de invierno, mientras que la ganadería vacuna queda en los pueblos. En estos casos el pasto que encuentra la vacada por los alrededores del núcleo de población no es suficiente y hay que completarlo con la hierba recogida y almacenada durante el verano. Ello explica la subordinación de la agricultura a la ganadería.

También es conveniente referirse a la importancia que merece la leche en estas comunidades de montaña. Los ingresos económicos que comporta son considerables. Indagar sobre el volumen de litros que suministra el pueblo, destino, comercialización, productos derivados, etc. son cuestiones que enriquecen esta temática. Para su logro el grupo-clase podría organizarse en equipos de trabajo, responsabilizándose cada uno de ellos de un aspecto. Una vez indagado y obtenidas unas conclusiones, éstas se someterian a debate general, intentando, con ello, valorar su significado en el conjunto comarcal.

\section{La agricultura}

Si la ganadería y los pastos son fundamentales en la economía de determinados pueblos montanos, para otros lo es la agricultura. La ausencia de pastos naturales genera que la cabaña ganadera mayor ofrezca un interés secundario, a no ser de la existencia de un ganado vacuno o de cerda estabulados. De todas formas lo que ahora interesa es descubrir la importancia del campo en este segundo grupo de comunidades montañesas.

9 Un excelente artículo sobre ello se encontrará en J. VILA VALENTi, "Una encuesta sobre la trashumancia en Cataluña". Pirineos, n. 17-18, 1950, pp. 405-445. 
Los ejemplos más claros quizás los reflejen aquellos pueblos instalados en las Cordilleras Béticas, de manera precisa los asentados en el núcleo Nevado-Filábride, entre las provincias de Granada y Almería. La acusada aridez que se detecta en estos medios montañosos durante un buen número de meses conlleva escasez de pastos en las alturas. A lo sumo, las zonas mejor expuestas y aquellas otras que mantienen un elevado grado de humedad en el suelo, generado por la larga permanencia nival, son las que mantienen rodales de pasto fresco durante el verano. Son los "borreguiles", espacios enclavados, casi siempre, en concavidades de los circos o en los tramos más elevados de los valles glaciares de Sierra Nevada.

La agricultura en estas comunidades andaluzas es preponderante y menguado el interés por el ganado, tal como lo afirma J. BOSQUE (1971, pág. 546) «En conjunto, Sierra Nevada es una cordillera de campesinos, teniendo escasa importancia, hoy como ayer, la ganadería..." Ello hace que la preocupación del hombre se dirija a la tierra. En este sentido el cuidado de los cultivos de secano y regadío llenan la mayor parte de su vida. Su dedicación al campo es tal que en palabras de P. DEFFONTAINES (1972) el agricultur aparece como un arquitecto de su campo, pues casi siempre ha tenido que edificarlo a costa de remover toneladas de tierra para alisar las vertientes. De esta manera construye sus bancales, tan típicos en las cordilleras mediterráneas.

Sobre estas cuestiones y otras similares podría enfocarse el estudio del medio agrario de los pueblos de montaña. Como objetivos referenciales a conseguir caben destacarse:

- Valorar la existencia de una agricultura de secano y de regadio.

- Identificar en el mapa municipal los espacios agrarios y explicar razonadamente su ubicación.

- Comprender la ordenación y fijación de los campos así como el uso del agua de riego.

- Conocer los sistemas y plantas de cultivo al igual que la producción agraria y su destino.

- Entender el significado de la casa del campesino como una herramienta más de su trabajo. 
- Interpretar y representar cartográficamente datos estadísticos.

El tema de la agricultura, como se comprenderá, es amplísimo por lo que se hace necesario acotarlo. Su enfoque debe estar presidido por el empleo de la comparación, es decir, por el establecimiento de confrontaciones entre formas de vida de estos pueblos agrícolas y aquellos otros ganaderos, principalmente. Una actividad interesante que nos permitirá fijar el espacio agrario será descubrir el nivel superior de los cultivos (altitud topográfica que éstos alcanzan a lo largo de las laderas), muy diferente según sea la cadena montañosa y la orientación de sus vertientes. Así, en el Pirineo meridional mediterráneo no sobrepasan los $1.600 \mathrm{~m} .{ }^{10}$, mientras que en Sierra Nevada pueden detectarse cultivos temporales de verano hasta los $2.400 \mathrm{~m} .{ }^{11}$. Indagar en este sentido resultará sumamente útil, pues habrá que relacionar clima, pendiente topográfica, planta, período vegetativo, sistema de cultivo, recolección, etc.

La confección de un mapa de cultivos mediante simbología preestablecida por los alumnos es otra actividad interesante. Resultará más enriquecedora si se compara el uso actual de la tierra con el de años pasados. Esto podremos obtenerlo pidiendo información a los propios campesinos, a la Cámara Agraria y a la Hermandad de Labradores y Ganaderos del pueblo. Como punto de partida por lo que respecta a su distribución espacial, la foto aérea de 1956-57 (vuelo nacional del Servicio Geográfico del Ejército) es una excelente referencia.

Con respecto al tamaño de las explotaciones agrícolas y al régimen de propiedad de la tierra y con vistas a la confección de gráficos a partir de datos estadísticos, los suministrados por el Censo Agrario de España (1962-19721982) resultan beneficiosos. También el Catastro es de suma utilidad.

Cuestión especial merece el tratamiento de las aguas de riego pues su uso se encuentra administrado, casi siempre, por las Comunidades de Regantes de los municipios. El estudio de las acequias de riego (origen, distribución en el espacio agrario, régimen jurídico, etc.) es sumamente atractivo y más aún

\footnotetext{
${ }^{10}$ Los cultivos más elevados los hemos encontrado a $1.712 \mathrm{~m}$. en Les Pardines (Parroquia de Encamp. Andorra). Se trata de campos temporales dedicados a tabaco.

$"$ La presencia de estos cultivos de temporada conlleva la permanencia más o menos prolongada del campesino. Para ello hace uso de los "cortijillos", edificaciones que le sirven de morada y almacén de aperos, principalmente, durante su estancia, que, generalmente, es de junio a septiembre.
} 
en aquellos casos en que el agua que canalizan no es exclusiva de un sólo núcleo de población sino que es compartida con otros. Dedicar atención a todo ello merece la pena. En la investigación que perfilamos no debe olvidarse la realización de un croquis general de las principales acequias que transcurren por la vega, con especificación de las áreas agrícolas que se aprovechan de sus aguas. También habría que tratar acerca de la figura del Administrador, como encargado de llevar el control de las mismas.

Un nuevo aspecto a considerar lo compone la casa del campesino montañés. De por sí aglutina una temática amplísima pero en este caso es un apartado más a estudiar, al igual que también cabría hacerlo cuando nos referimos a los pueblos ganaderos.

La casa de campo configura una herramienta de trabajo pues en ella se guarda el utillaje, los frutos recolectados, las semillas. Sirve, además, de morada al campesino y su familia y, en muchos casos, como por ejemplo en pueblecitos del Sistema Ibérico, Cordillera Central y Cordilleras Béticas, la planta baja de la casa se utiliza para albergue del animal de tiro y almacenaje de paja. Incluso el tejado es objeto de determinada utilidad, a veces dispuesto para que pueda captar el agua de lluvia y enviarla a un aljibe, o simplemente liso, en terraza, para poder secar frutos al sol. Ahí está una primera actividad: descubrir la organización y utilidad de la casa (Fig. 4).

Otra sugerencia didáctica es la observación y análisis de los materiales empleados en la construcción de ella, asi como las formas dominantes, desde su aspecto externo (fachada, dimensión de las aberturas exteriores) a la techumbre. En este sentido se hará notar que las casas más antiguas de los pueblos están edificadas con materiales que proporciona el medio circundante. Los muros, de piedra, de arenas, de piedra y arenas machacadas, de argamasa, etc. y los tejados, de tierra, tejas, losas, etc. Los techos también varían en cuanto al material empleado. En la Alpujarra, por ejemplo, no es extraño observar este hecho. En unos pueblos el techo lo conforma un entramado de cañas que descansa sobre un armazón de vigas de madera de álamo, mientras que en otros, donde aquéllas escasean, lo compone un enlosado de pizarra (lastras) retenido por el referido armazón.

En la actualidad los sistemas tradicionales de construcción raramente se emplean, pues ni los materiales ni los patrones arquitectónicos son los mismos. Descubrir las causas de ello debe ser, igualmente, motivo de estudio. 
FIGURA 1. REPRESENTACION GRAFICA DEL REGIMEN TERMOPLUVIOMETRICO DE BACARES (ALMERIA).

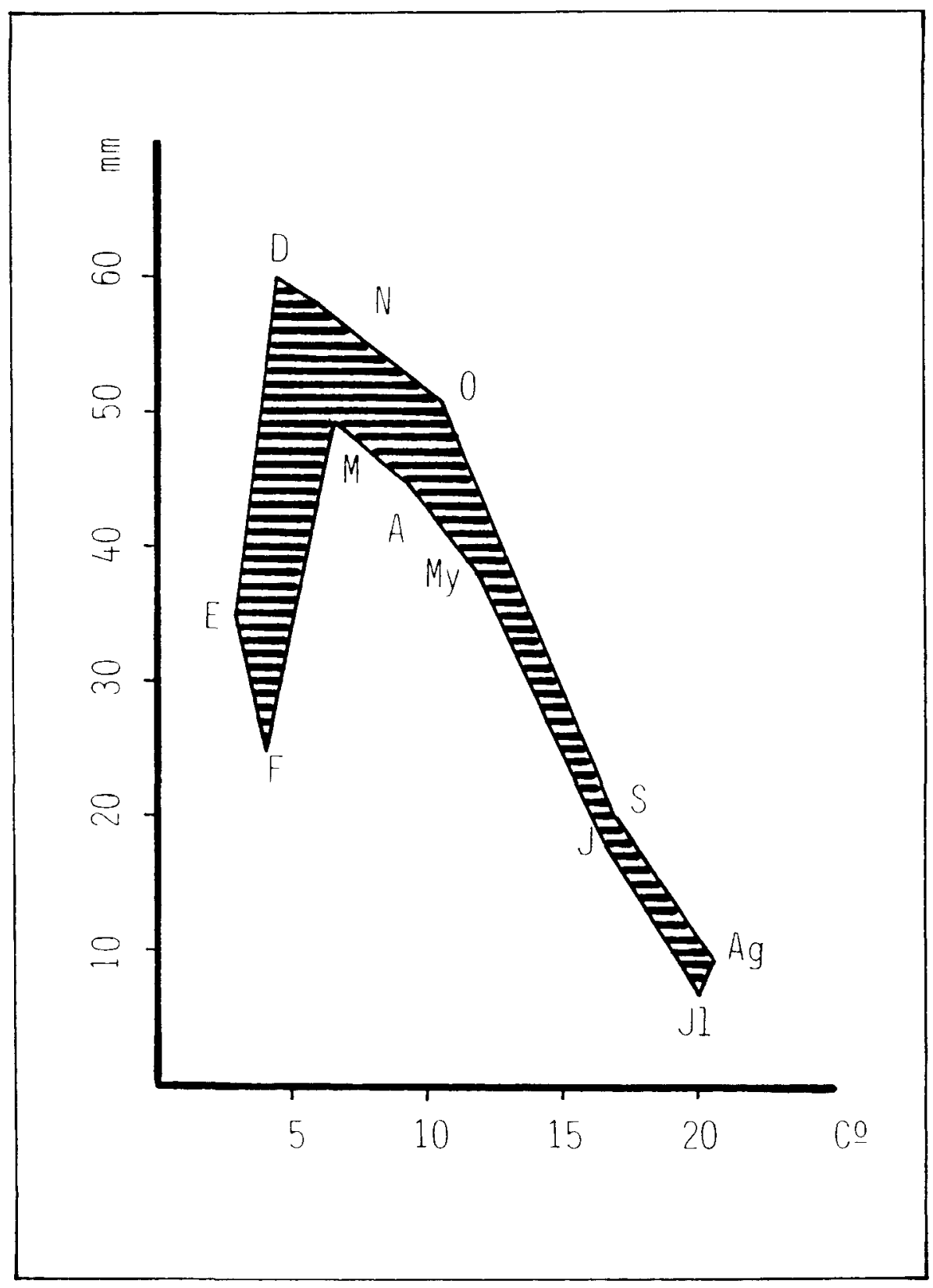




\section{FIGURA 2. DIAGRAMA OMBROTERMICO DE GAUSSEN DE LA ESTACION DE MONZON (HUESCA).}

Se consideran meses áridos aquellos que la temperatura media multiplicada por dos supera el valor de la pluviosidad del mismo mes $(2 t>p)$. En el gráfico queda reflejada la aridez porque la curva de temperatura permanece sobre la pluviosidad.

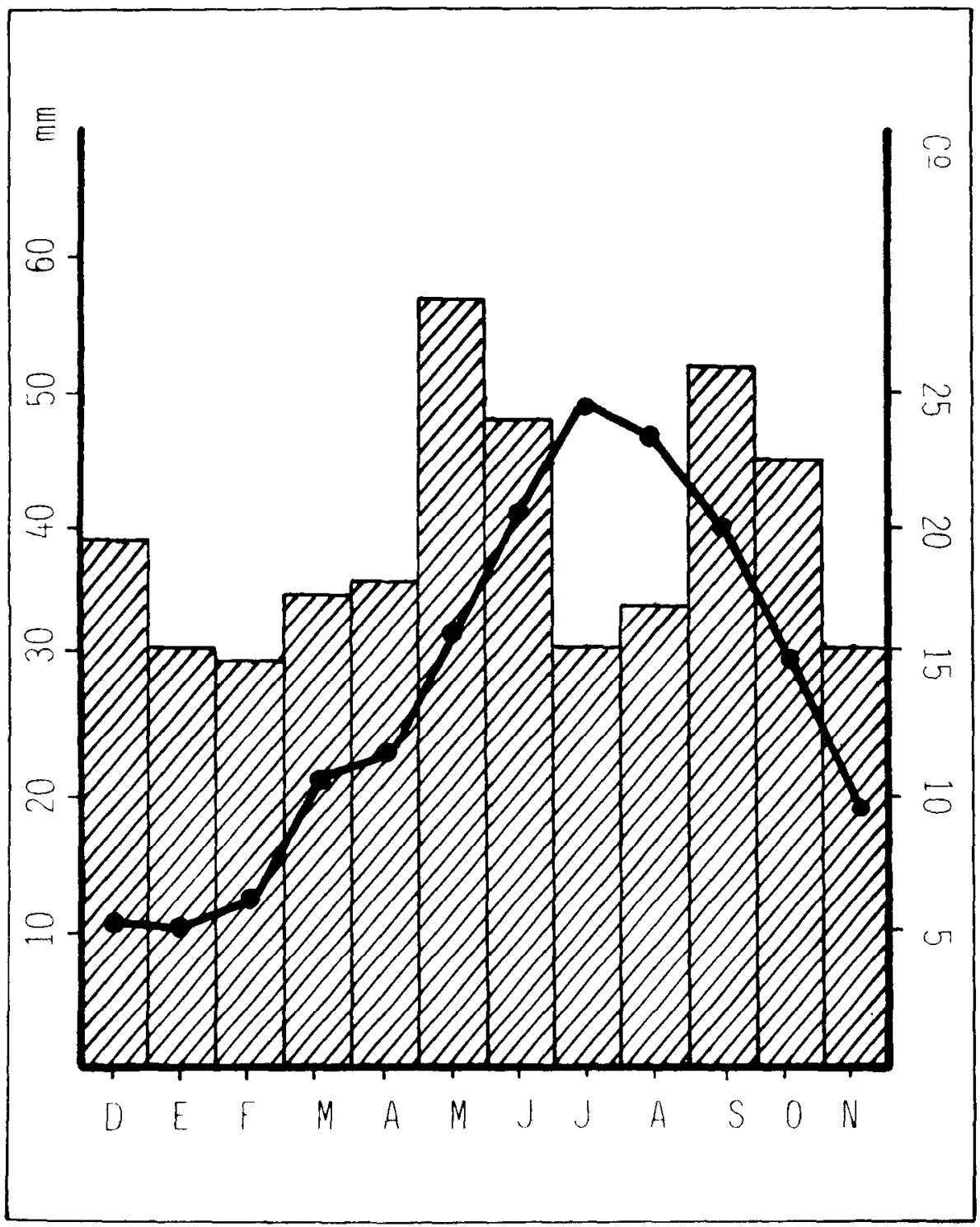


FIGURA 3. MAPA DE LAS PRINCIPALES CAÑADAS DE CATALUÑA (J. VILA VALENTí, 1950)

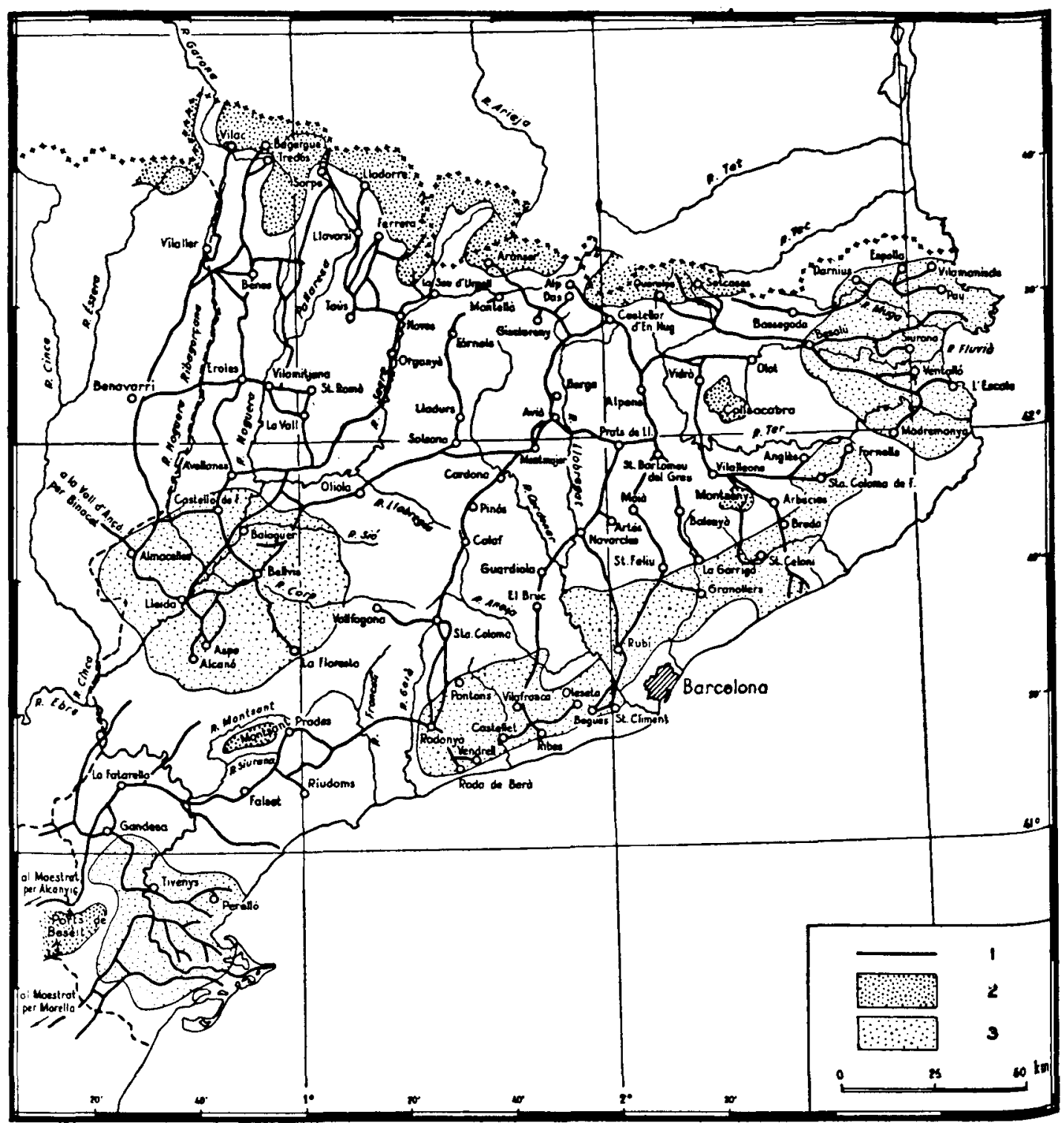

1. principales cañadas.

2. pastos de verano.

3. pastos de invierno. 

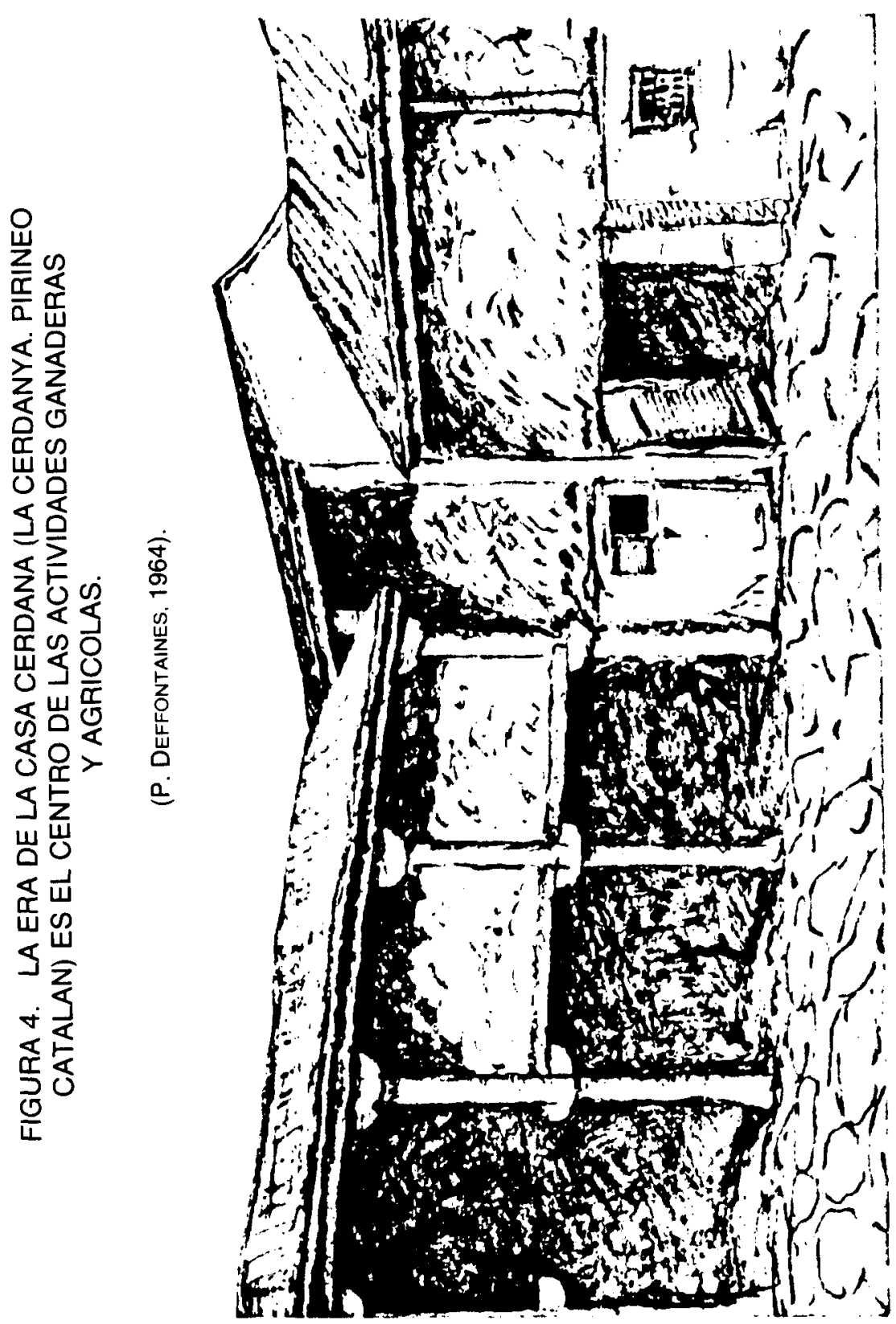